\title{
DEALING WITH EXISTENTIAL SUFFERING OF PATIENTS WITH SEVERE PERSISTENT MENTAL ILLNESS: EXPERIENCES OF PSYCHIATRIC NURSES IN FLANDERS (BELGIUM)
}

Christophe Moonen - Joke Lemiengre - Chris Gastmans

\begin{abstract}
Residential psychiatric patients with severe persistent mental illness are often confronted with unbearable existential suffering. This qualitative study aims to describe how psychiatric nurses in Flanders (Belgium) deal with these patients. In view of the data we describe the nursing support for the existential suffering of these patients in terms of a process-related development. In this process of care four phases can be distinguished: meeting and knowing the patient, acknowledging the patient as an individual and as a sufferer, building a personal caring relationship based on a bond of trust and on respect for the patient as person, and a concluding phase. The personal caring relationship between nurse and patient is the fundamental element in the care practices. Next we describe the contextual framework inasmuch it can influence the caring process in a restricting or stimulating way.
\end{abstract}

\section{KEYWORDS}

severe persistent mental illness, existential suffering, psychiatric nursing, nurse-patient relationship, palliative care, euthanasia, ethics 


\section{INTRODUCTION}

Patients with severe persistent mental illness (SPMI) suffer from a prolonged or recurrent mental illness, are impaired in activities of daily living and require long-term treatment (Ruggeri et al. 2000; Woods et al. 2008). These patients are vulnerable, with multiple comorbidities and higher-than-average mortality rates with impact on their life expectancy (De Hert et al. 2009; Chang et al. 2011; Laursen 2011). The term 'SPMI' is used to point out that the patient's pathology is qualified as being chronic or resistant to therapy, thereby necessitating a lengthy stay in a psychiatric residence or frequent contact with such an establishment. Specific therapeutic interventions ('cure') are often less effective, bringing the necessity and power of 'care' more to the forefront.

Unbearable existential suffering of patients with SPMI is an insufficiently recognized problem in mental healthcare (Nyström et al. 2002; Hem \& Heggen 2003; Haekens \& Hermans, 2008; Wagner et al. 2011). 'Unbearable existential suffering' is a dynamic, hard to define phenomenon that is nevertheless closely connected to the subjective quality of life experienced by the patient. The suffering can stem directly from the psychiatric problems in question and/or it can result from the context in which the patient finds himself. Qualitative research among patients afflicted with schizophrenia indicates that existential suffering can be caused by a number of factors: the need for personal development and the search for meaning, the need to be respected and not stigmatized, and the loss of autonomy and self-esteem (Wagner et al. 2011). Nyström et al. (2002) and Erdner et al. (2005) describe through interviews with people suffering SPMI that they experience an existential loneliness due to difficulties in the development of human relationships. Being confronted with hopeless existential suffering of patients with a long-term need of psychiatric care invokes some ethical questions about the content and the meaning of the therapy and care provided to these patients. Should medical treatment be continued? What is the patients' quality of life? How should we deal with the patients' requests concerning the active termination of life?

In Belgium, the Netherlands and Luxembourg, the acknowledgement of hopeless existential suffering among this group of patients has led to the acceptance of this form of suffering as a justification of euthanasia (Belgian Act on Euthanasia 2002; Dutch Termination of Life on Request and Assisted Suicide (Review Procedures) Act 2001; Luxembourg Euthanasia and Assisted Suicide Act 2009). In these countries, competent 
people that are afflicted with unbearable mental suffering can submit a request for euthanasia. The term mental suffering is here used as distinct from physical suffering. The necessary conditions for euthanasia on the basis of unbearable mental suffering that need to be met in Belgium are the following: the request has to be assessed by three doctors, and one of these has to be specialized in the disorder the patient suffers from. Furthermore, the request has to be expressed voluntarily, deliberately and repeatedly by a patient who is in a medically determined state of unbearable mental suffering without prospects. Since the euthanasia Act has come into force in Belgium in 2002, an increase has been observed in the number of reported cases of euthanasia based on unbearable mental suffering: from four registered cases with a neuro-psychological affliction in the timeframe of 2004-2005 to 67 registered cases in 2013 (Federal Control and Evaluation Committee on Euthanasia 2014). However there are no exact numbers at this time concerning the actual number of cases of euthanasia based on unbearable mental suffering.

Recently there has been an emergent debate about the possible role of palliative care in dealing with hopeless existential suffering in mental healthcare (Haekens \& Hermans 2008). Subjects with SPMI involving hopeless existential suffering raise the need for high-quality support and guidance within the framework of palliative care (Sweers et al. 2011). With palliative care, the immediate goal is not so much the cure of the patient as providing an optimal quality of life in the physical, psycho-social, existential and spiritual sphere (WHO 2002).

The content meaning of palliative care in the context of mental healthcare has not yet been sufficiently explored (Haekens \& Hermans, 2008). Apart from conceptual uncertainties, there also have been only very few attempts at empirical investigation (Woods et al. 2008; Lloyd-Williams et al. 2014). Moreover, the available research regarding palliative care for patients with SPMI is limited to unbearable physical suffering that present themselves in the terminal phase. No study was found regarding palliative care that accommodates hopeless existential suffering that presents themselves in the non-terminal phase (Sweers et al. 2011). There are however comments indicating the real need of such care (McGrath \& Hamish 2004).

With their broad background - physically as well as mentally, socially, existentially and spiritually - and through their interpersonal relationship with patients and their environment, psychiatric nurses are often the closest caregivers to be confronted with the hopeless existential suffering of patients with SPMI. These nurses assume 
responsibility for the patients assigned to them, and strive for patient-oriented, continuous, high-quality and expert support and guidance. Research into the role and experiences of psychiatric nurses in the assistance of patients with PSMI afflicted with hopeless existential suffering seems to be non-existent. This research aims at describing the characteristics of the care process for hopeless existential suffering of patients with SPMI, specifically from the psychiatric nurse's perspective.

\section{Research question}

How do psychiatric nurses deal with patients with SPMI with hopeless existential suffering? 


\section{METHODS}

\section{$\underline{\text { Design }}$}

We have chosen a qualitative research design with semi-structured interviews. Data collection and analysis were inspired by the Grounded Theory approach. This approach guides the systematic inductive study of a phenomenon that requires a thorough exploration and that can serve as the potential foundation for formulating a theory (Corbin \& Strauss 2007).

\section{$\underline{\text { Data collection }}$}

The setup of the sample survey, data collection and data analysis were framed in an iterative process. Semi-structured in-depth interviews are at the core of the collected data.

Five psychiatric hospitals in Flanders (Belgium) were selected and invited to participate in the study. All five hospitals gave their consent to participate. In the sampling of the psychiatric hospitals all provinces of Flanders were represented, there was a variation of size, type of institution (private versus public) and conviction (Christian versus neutral).

Subsequently the sample survey of the nurses took place in two phases. In the first phase of purposive sampling a sample was taken of nurses with following inclusion criteria: it concerns a psychiatric nurse (1), with a daily responsibility for the care of patients with SPMI afflicted with hopeless existential suffering (2) in the context of a psychiatric hospital that is selected for the study (3), having the Dutch language (4), and willing to participate in an interview (5).

For each hospital one contact person was appointed to facilitate the recruitment of nurses. Nurses who were eligible to be interviewed were asked to fill out a questionnaire concerning personal characteristics and their expertise in the care of patients of the target group as described. In the end 87 questionnaires were returned to us. Based on these, eight nurses were selected for the purpose at hand. In drawing up the list care was taken to achieve maximum heterogeneity (sex, age, work experience, conviction, level of education), in order to allow semi-structured in-depth interviews with the nurses in question to describe as wide as possible a variety of experiences. In 
the second phase of theoretical sampling, we selected four psychiatric nurses working in wards that focus specifically on 'palliative' care and three psychiatric nurses that had been confronted with requests for euthanasia from patients in a non-terminal phase. In total, 15 psychiatric nurses were interviewed (cf. Table 1). 


\begin{tabular}{|llll|}
\hline Table 1. Sample characteristics of participating psychiatric nurses (n=15) & \\
\hline Seks & & Type of unit & 1 \\
Male & 7 & General psychiatry & 1 \\
Female & 8 & Structuring Care & 3 \\
& & Psychosis Unit & 2 \\
Age & & Psychiatric Nursing Home & 1 \\
$20-29$ & 3 & Observation unit & 2 \\
$30-39$ & 5 & Gerontopsychiatric Unit & 1 \\
$40-49$ & 5 & Eating Disorders & 2 \\
$50-59$ & 2 & Long-term Intensive & \\
& & Treatment Unit & \\
Level of education & & & 1 \\
HBO5 & 6 & Work experience & 1 \\
Bachelor & 9 & $<1$ & 3 \\
& & $1-5$ & 3 \\
Religious or philosophical orientation & $6-10$ & 3 \\
Roman Catholic & 9 & $11-15$ & \\
Humanist & 4 & $16-20$ & \\
Spiritual (Not & 2 & $21-25$ & \\
committed to an & & & \\
official religion) & & & \\
& & & 2 \\
\hline
\end{tabular}


The interviews were conducted between March 2013 and February 2014. We invited each nurse to describe the care process for patients with SPMI on the basis of a particular case. The main question we asked in preparation for the interview was: 'can you describe a concrete trajectory of care for a patient with SPMI and with existential suffering in which you were closely involved. In total 20 cases were brought up during the interviews. The interviews were conducted by one researcher $(\mathrm{CM})$. The interviewees described their care for patients suffering from diverse psychiatric pathologies that can be found in the DSM-5. Some of the nurses described a trajectory of care for two or more patients. The major psychopathologies that were mentioned: Bipolar Disorder=4, Borderline Personality Disorder=3, Psychotic Disorders=5, Alcohol Dependence=1, Major Depressive disorder=2, Eating Disorder=2, Autism Spectrum Disorder $=1$.

The interviews took about 60 minutes each, were recorded digitally, and written out verbatim. To each in-depth interview a report was added with contextual data on the course of the interview.

\section{$\underline{\text { Data analysis }}$}

The 'Qualitative Analysis Guide of Leuven' (QUAGOL) facilitated the process of data analysis (Dierckx de Casterlé et al. 2012). Saturation of the data was achieved. Per interview, after repeated reading, a thorough reflection report was written, describing the most important concepts characterizing the nurses' experiences and categorizing and sub-categorizing them in a conceptual diagram. Data collection and analysis took place simultaneously and systematically. Their development was of a cyclical nature, because of the constant comparison of content-related topics from earlier in-depth interviews and adjustments of the preliminary findings. This cyclical process took place both during the survey and during the analysis. The analysis was made possible by the QSR NVivo software program.

\section{Trustworthiness of findings}

A number of strategies that are characteristic to qualitative research were applied to increase the trustworthiness of the results (Denzin \& Lincoln 2000).

The personal and professional status of the researcher (CM), his knowledge on the subject due to preliminary investigation and secondary research, possible expectations 
with regard to the inquiry, etc., were all written down to transcend subjective prejudice. An audit trail was kept during the entire course of the investigation. All decisions that were taken, all difficulties that cropped up, and all changes to the original plans were painstakingly registered. All interviews were read by three researchers (CM, CG, JL). The course of the investigation and the analyses are followed up closely and critically by the supervisors (CG, JL), allowing them to make the researcher adapt his approach wherever necessary.

\section{$\underline{\text { Ethical considerations }}$}

The study protocol was approved, along with informed consent forms and information sheets, by the management and the ethics committees in each of the hospitals involved. All participants received written information about the investigation and were asked to give their informed consent. The anonymity of the participants and the participating hospitals was guaranteed, and the data were treated with strict confidentiality. 


\section{FINDINGS}

In view of the empirical data we can describe the nursing support for the hopeless existential suffering of patients in need of long-term care in terms of process-related development. In this process of care we can distinguish four general phases: meeting the patient, acknowledging the patient as an individual, building a personal caring relationship, and a concluding phase. The personal caring relationship between nurse and patient is the main element in this procedure. This relationship doesn't just appear out of nowhere: it takes effort, from the moment of the first acquaintance on. During the first meeting we can establish whether there is a potential connection. If nurse and patient 'click', the patient can be acknowledged both as an individual and a sufferer. These are the foundations upon which the caring relationship is built. However, the above-mentioned general phases in the process of care shouldn't necessarily be viewed as successive stages: they are simply four pillars upon which the process of caring as described by the interviewees can be developed. In the following we will describe each of these four components separately. Next we will describe the contextual framework inasmuch as our data suggests it influences the caring process. The influence of these contextual factors can either be restricting or stimulating. As a whole, the process of care is rendered schematically in figure 1.

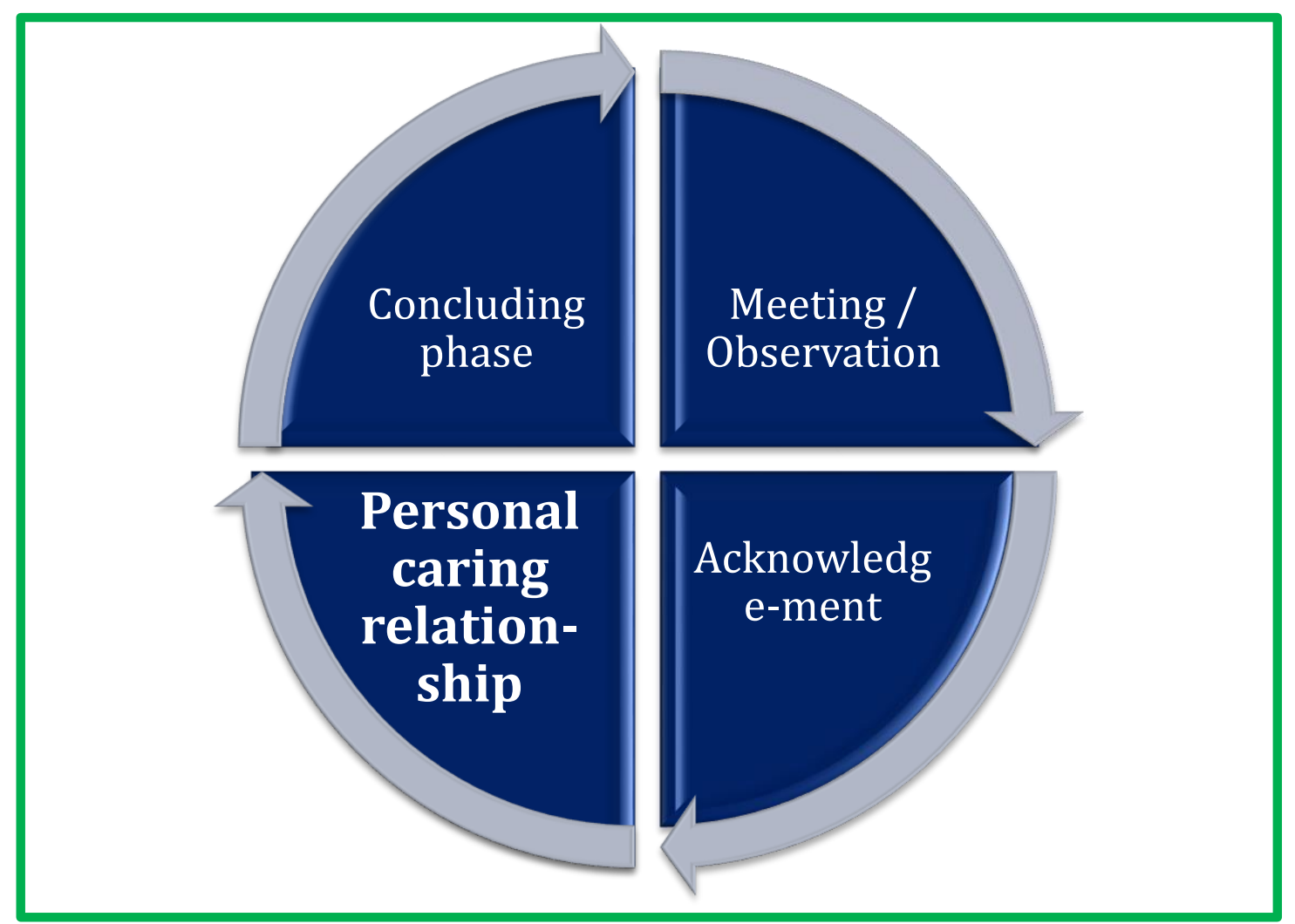




\section{Description of the process of care}

\section{First meeting}

From the perspective of the nurses we interviewed, the first component in the process of care is getting acquainted with the psychiatric patient. This first acquaintance can be seen in two ways: on the one hand as the initial stage of getting to know each other, on the other hand as an act of observation that continues throughout the process of care. In a strict sense, we mean here the act of first getting to know the patient.

The majority of the nurses we interviewed tries first of all to evaluate the patient. This they do in various ways, but in general terms we can distinguish an orienting phase.

\footnotetext{
"What we always do with our people really: when they come here, we plan a first period (...), a month of observation. This is an orienting phase for us, in which we gather information about what goes on at home, how we can tell, what we can glean from the context. This is the kind of information we'll be collecting." (nurse 3)
}

Several nurses talk about 'trying to get closer' to the patient. According to some interviewees, this can be achieved by adopting an expectant manner vis-à-vis the new patient, as is illustrated by this quote:

"The mentor actually introduced me once, he said: right, this is $X$, (...) your comentor. So I took on an expectant pose, and this woman started telling me about all sorts of things, so you just kind of go along with that. But other than that, at first I always hold back and see how things go. You have to make sure people don't miss their opportunity, don't you? You have to withhold a bit, make observations on who it is you've got in front of you, so you don't go and say anything stupid." (nurse 10)

According to four interviewees, however, this first meeting can also take on the form of an active questioning of the patient, in order to reveal his particular preferences as to the optimal form this care-giving can take: 
"So I think at first I asked her an enormous amount of questions: is it ok if I do this now? Or can I do this? It's really a matter of sounding them out and taking note: what does she like? What does she want? And yeah... through the years, eventually you get to know her habits, don't you?" (nurse 12)

The findings acquired during this first meeting can be adjusted regularly. According to one interviewee this can be linked to the patient's limited means of communicating things, since due to his pathology or mental deficiency the patient is not always equipped to express his wishes or complaints adequately. Another nurse mentioned how some patients can be a bit reserved or withdrawn, causing the observation period to take more time. Several nurses in fact speak of the observation and the act of getting to know the patient as something that goes on throughout the entire process of care.

2. Acknowledging the patient as an individual and a sufferer

Acknowledgement plays an important part in the nurse's support of the existential suffering of patients in need of long-term psychiatric care. First of all, most caregivers try to acknowledge the patient as a full individual, transcending his status as a patient or the specifics of his medical condition.

'Very often patients have been rejected and discarded, people [say]... "yeah, that's a nutcase" or "this is this" and "that is that", and these people end up isolated. But when they get a chance to be a person again, yeah, they can feel that... In fact, our people, our patients, they are very sensitive men and women, in fact I think that's why they develop a disorder, because they are so sensitive. If you can give them that, if they can feel that (...) you're off to a good start, if you ask me." (nurse 3)

A little over half of the interviewees talks about truly noticing and genuinely listening to the patient, stemming from a sincere interest in who this unique other person really is. This can be revealed in little things, like a friendly greeting in the hallway, a chat about the patient's preferred subjects such as their favorite TV shows, or simply sitting 
by their side every now and then. One nurse mentioned this initial mode of acknowledgement in these terms:

"It doesn't have to be much, just, you know... not like I'm running through these halls and sure, I've seen you and you in passing, but just asking everyone individually a question a now then, or simply showing an interest, like: ok, there you are, then. (...) As long as they can tell, they're paying attention to me, I do matter, after all, or I have my place here, right?" (nurse 10)

Five interviewees reported that this kind of recognition becomes possible from a sense that patient as well as nurse are in the end just human beings, and that it is important for the patient to feel that it is fine for him to simply be there as a human being especially as a human being, no matter what his individual identity may look like.

Apart from this acknowledgement of the patient as an individual, virtually all interviewees mention the importance of acknowledging that individual's suffering. Ten nurses try to go along with the existential suffering, to share in this pain to the extent that this is possible, without immediately linking it to this or that particular psychiatric pathology. This suffering is not always easily seen or detected, so one of the nurses displays an active alertness in these matters:

"Taking the suffering seriously, mainly. And having the courage to talk about it, to comment on it yourself every now and then. Especially if people have talked about it themselves, earlier, but maybe also if they haven't, sometimes. Daring to ask those questions, at times: 'Do you sometimes feel like you can't take it anymore?' Just broaching those topics, anyhow. You can tell that the patients don't always dare to start these discussions themselves. It's a way of recognizing them." (nurse 9)

According to four interviewees, acknowledging the individual in his suffering relates also to the request for euthanasia:

“Acknowledging that question, that it's there, and we can't just shove it aside and go 'You're ill, that's not going to happen, that doesn't apply to you.", (nurse 7) 
Some caregivers also mention that this is a sensibility that needs to be maintained, especially in view of the often persistent anguish and the ever repeating complaints among patients of this type. One nurse says this can involve trying to sympathize with the agony caused for instance by delusions in patients suffering from schizophrenia, even if it is hard for the caregiver to actually 'feel' these delusions.

\section{Developing a personal caring relationship}

Based on a positive first meeting on the one hand and the acknowledgement of the patient as an individual and a sufferer on the other hand, the caregivers we interviewed want to be or do something meaningful for the psychiatric patient afflicted by hopeless existential suffering. In other words, the two above-mentioned components make up the conditions on which a caring relationship can be developed. This personal caring relationship is based on the bond of trust that is the consequence of respecting the entire individuality of the patient.

\subsection{A personal relationship between nurse and patient}

Fourteen of the caregivers we interviewed talk first of all about creating and maintaining a 'bond' with the patient. 'Together' is an adverb that crops up often in the interviews, as in: 'to start out together', 'to fight it together', etc. A good operating base for this is the system of 'mentor' or 'individual nurse', a caregiver who is assigned to a specific patient (along with a colleague or 'co-mentor', or not) in order to be able to follow a patient more carefully. This way many caregivers indicate they can have more frequent contact with the patient and there is some continuity to the relationship, as well as the possibility of an individualized approach. With a special bond like this, one truly gets a chance at getting to know the patient well. A couple of interviewees stressed that this caring relationship can also be a significant catalyst in working towards a common goal, and that this creates an opportunity of approaching the same patient from a number of different perspectives.

\subsection{Based on a bond of trust}


The majority of the nurses we interviewed indicates that the personal caring relationship between patient and nurse is based on trust. Some claim that, in this trusting atmosphere, patients are encouraged to broach subjects that aren't easily talked about, such as a request for euthanasia. Several nurses add that this bond of trust isn't just there, it has to be built: trust accumulates with time.

About half of the interviewees also indicate that this is a vulnerable process.

“Afterwards, judging by her reaction, maybe it wasn't the right way for her to move like that after all. It did turn out OK in the end. But it took quite a bit of time, and many more talks, to rebuild that bond of trust." (nurse 8)

In other words the nurse tries to establish a bond of trust, and hopes that this trust is reciprocated, so that we can properly speak of true mutual trust. Making clear arrangements can be a way to solidify this feeling of mutual trust.

3.3. With respect for the patient as a complete individual

The personal caring relationship that is based on a bond of trust focuses on consideration of and respect for the patient's entire individuality. Attention is paid to the complete person from a non-reductionist, in other words a holistic point of view. Not only the psychic, but all human dimensions are acknowledged and admitted in the process of care. One nurse summarized this attention for the complete person as follows:

"It's about paying attention to a person's different dimensions, both specifically and in their connection to each other: the physical, mental, relational and social context (...) and the opportunity to find meaning and purpose." (nurse 11)

In most of the interviews there is talk of the spiritual dimension. Spirituality can be understood both in a broad and in a narrow sense. In a narrow sense it is about respect for a religious need. One of the interviewees, for instance, acts as 'antenna person' in spiritual matters, and really embodies this function: 
"I had this young woman, borderline case, who was really depressed and couldn't sleep night after night (...). And then it turned out that she was a christian (...). By intuition, when she was really at her wits' end, I just said to her: 'Would you like for us to pray together?' And we did, we prayed together." (nurse 1)

Other nurses point out that this dimension can be understood in a broader sense, like this one interviewee who sees this search for meaning at work in specific situations such as meetings between people or nature walks, or this other one who respectfully tries to go along with a patient's passion for development assistance.

In virtually all of the interviews attention is paid to the social dimension of the patient. This is particularly relevant in involving patients' relatives or loved ones in the process of care. There can be various reasons for this: prompted by the therapeutical context (what is the interaction with the patient like?), strengthening the ties with existing contacts, supporting family members and loved ones, involving family members in serious decisions (such as euthanasia), sharing responsibility (not all care should be left to professional caregivers). Five nurses point out that consideration for the social dimension can also mean promoting participation in everyday social life, like going to market with a patient or having a cup of coffee together outside of the hospital grounds. One interviewee mentioned the beneficial effect of contact with volunteers.

Attention for the physical dimension has several aspects as well, such as daily physical care, but also recognizing specific somatic complaints. One interviewee, for instance, thinks that psychiatric institutions sometimes over-psychologize their patients:

"She was also happy that I had acknowledged that, while she was used to hearing things like 'It's just between her ears', 'It's a mental case, she is a sick woman.' Sure, but there is a physical issue here as well, isn't there?" (nurse 1)

Another thing that can be classified within this physical dimension is the power of physical contact, like a pat on the shoulder, a hug, or a beauty cure.

Most of the interviewees also pay attention to the specific mental dimension of patients. We mentioned earlier the example of taking seriously the mental strain put on patients with schizophrenic delusions. Where the specifically somatic can sometimes be 
overlooked in psychiatry, apparently the opposite is also possible. One interviewee mentions in this context:

"The process of care is also put within a specific timeframe, and the mental aspects is sometimes lost sight of. I think this is really too bad." (nurse 12)

Finally there is also the moral dimension. By this we mean that a patient's moral responsibility or his ability to make autonomous choices should be taken seriously:

"We feel that therapy is hard, because people have to take steps that are really hard for them, or refrain from doing things they are often susceptible to. And we feel that this can only truly work when they are behind this and choose for it themselves. (...) So this autonomy, making their own decisions, that is really very important." (nurse 8)

In the context of euthanasia, too, all caregivers who are confronted with this request urge us to take these wishes seriously, if they can be seen to result from the patient's autonomous choices.

"I can only make my peace with this if someone has carefully considered it and we have tried everything, with all involved, to try to create a new sense of purpose, new perspectives, new meaning. (...) If people share this, and they have made their choice in a very existential, very considered way, I can accept it as a product of their autonomous thinking." (nurse 8)

\section{Concluding phase}

Even when dealing with patients who are in need of long-term psychiatric care, the caring process can also come to a close. This concluding phase is discussed explicitly by eight caregivers. Three of our interviewees mention cases where patients resigned without there being any further information, successfully committed suicide, or were transferred to another hospital because their condition was deteriorating. Five nurses specifically note that the caring relationship does not end but, because of its personal 
nature, continues to make itself felt. Continuing this relationship between caregiver and patient is reported to be possible in a number of ways. This can happen in the context of mandatory or voluntary follow-up care, by keeping in touch after dismissal (for instance through correspondence), or by the occasional contact after a patient has been transferred to another ward. Nor does the caring relationship have to end when a patient dies: a memorial service can be organized in the hospital ward, so that people can say their farewell in a dignified manner.

\section{Description of contextual factors:}

Inevitably, the caring relationship is framed in a specific context. This context can be either stimulating or restrictive to the relationship. Contextual factors as mentioned in these interviews can be categorized into three levels: the institutional level, the team level, and factors pertaining to the individual caring relationship itself.

\section{Stimulating contextual factors}

On the first, institutional level, the infrastructure or surroundings can enhance the caring relationship. One interviewee explicitly mentioned factors of this kind:

"For instance, we have a quiet garden here on the grounds, we have a building - and I think this is really beautiful - replacing the former chapel, where people of any creed, or no creed, can withdraw, meditate, find some peace of mind. Can I just mention this here? A lot of people in our ward are very restless. I talk to them about this: 'Go out for a walk, go to that quiet place and get back in touch with yourself.", (nurse 1)

On the team level various stimulating contextual factors are mentioned. Four interviewees indicate that the homely feeling accorded by the ward made for an added value in the eyes of psychiatric patients who have to spend extended amounts of time there because of their need for long-term care. This homely feeling or welcoming atmosphere benefits the patient population first and foremost, but two interviewees declared that the caregiver, too, needs to be able to feel at home. 
Furthermore there are those that claim to strive for a made-to-measure type of care, so as to be able to acknowledge the individual and his suffering. This care can take a number of forms, for instance when the ward is subdivided into more specific target groups:

\begin{abstract}
"We are also sort of splitting the patients into two groups now, because there's huge differences between patients here. We've got a whole mix here of people who don't have any structure left in their life, where we have to do everything for them, but also people who are still able to go to work, or, you know, who can take care of their own business. So we try to kind of separate these patients a bit. (...) That way, we have a structuring group and a protecting group, that's what we're trying to achieve really." (nurse 4)
\end{abstract}

This made-to-measure care can also come about because the therapeutic approach takes into account the chronically ill:

'You really have to tell them: right, there'll be other people here after you, we need these rooms, perhaps it's really meaningful to you to demolish this place, tear up the floorboards, God knows what else, but I'm afraid that just won't do. And then you look around for alternatives: what have we got to offer you? And then you go: a bread that you turn into all kinds of things, can it become something else? Can it be turned into clay, can it be a panel, can it be paint?" (nurse 15)

The importance of communication as a stimulating contextual factor is also underlined. Interdisciplinary relations, the opportunity to vent, and a climate of open communication: these are factors that will ensure that all subjects are debatable. This rings true especially when it comes to euthanasia. One interviewee mentions the presence of volunteers as an added value for the team. These people can fill in to some extent where the available time and attention of the nurses is limited.

Finally, on the level of the individual caring relationship, praise is accorded to the system of follow-up caregiving. Thanks to this system, the relationship is not fragmented among any number of nurses, and a bond of trust can promoted. In the context of personal follow-up care, half of the interviewees mention the 'duo system': 
by linking patients to two nurses instead of one, the process of caring is made more bearable for every individual nurse, the continuity of care can be guaranteed, and a bond of trust can be supported.

Restrictive contextual factors

On the institutional level, one interviewee states that unreasonable target figures can hinder good caregiving. Three other nurses indicate that a growing administrative responsibility jeopardizes the individual attention spent on each patient. A frequently recurring complaint is that the lack of single rooms can hamper patients' desire for rest. Some departments still make do with four-person rooms.

On the team level, we frequently hear about understaffing in the care ward, so that the individual presence of caregivers cannot be assured and it is not always possible to take into account patients' demands, some of them of a quite elementary nature. Likewise, five interviewees signal a lack of expertise, forcing nurses at times to take on other duties (for instance educational ones) beyond simply fulfilling their role as caregivers. Many also feel there is a shortage of therapeutic animation and psychological aid, making it hard to meet the patients' needs.

An important restrictive contextual factor that is mentioned by more than half of the nurses we interviewed, is negative countertransference towards the chronically sick patients.

"Often you could just feel it in the air. And among the team too it was talked about, how difficult it is. About her character, all of a sudden it was a character. You know the usual words. How she wanted to shake us up a bit and set us up against each other to some extent. Terms like that cropped up. Whereas - I didn't really feel that way. Some negative connotations came up. More of her behaviour was viewed in a negative light, and, for instance, we thought, as a team, that we should be more strict with her, or make new arrangements with her." (nurse 8)

About half of the interviewees also point out the dangers springing from an overly paternalistic attitude towards the patients: 
"I think one of the things that are typical for psychiatry in general, especially in observation wards and closed units is that we want to tend to everything. Consciously or not, we take care of everything in these people's place, and I think that can come across as patronizing, or less empathic." (nurse 7)

According to six interviewees, this paternalistic approach can be more specifically related to the excessive importance on the department's curative and formalistic vision, on account of which the patient's specific existential suffering is not always fully acknowledged. Moreover the patient's autonomy may be at risk when too many little things are taken care of in his stead. Four nurses complain about an insufficient appreciation for the caregiver's work. One nurse claims this is because she goes against the views that are prevalent in her ward, two others say that management or the ward's superior have grown alienated from the actual nursing work that is done there.

On the third level, the one regarding the individual caring relationship, four nurses report feeling inhibited by group-centered methods, whereas the patient is in need of an individualized approach. Some nurses also experience a shortage of additional training and supervision. 


\section{DISCUSSION}

Strengths and limitations of the study

Sample heterogeneity through purposive and theoretical sampling, enabled us to capture a variety of experiences of nurses. Audit trail, self-reflection and peer debriefing were strategies to ensure the trustworthiness of the findings. Although the sample size of 15 nurses was rather small, we reached saturation during the data analysis. Further triangulation through additional interviews from other perspectives (e.g. psychiatrists, psychologists, patients, relatives ...) would add substantial information to understand what kind of expertise, attitudes and skills are needed to deal appropriately with the existential suffering of patients with SPMI. Another source of bias relates to the difficulties the nurses had to choose a specific case to describe in the interviews. We noticed that it was hard for most of them to concentrate on the temporal structure of their narrative of care. Particularly in the first eight interviews we found it difficult to reach depth and to gain detailed information concerning how they cared for patients with SPMI with existential suffering. Therefore, in order to describe as wide as possible a variety of practical experiences, we selected in a second phase of theoretical sampling, four psychiatric nurses working in wards that focus specifically on 'palliative' care and three psychiatric nurses that had been confronted with requests for euthanasia from patients in a non-terminal phase. These interviews provided us more insights in the care process of psychiatric nurses for patients with SPMI with existential suffering and enabled us to reach saturation.

\section{Discussion of the main results}

On the basis of this study we identified that interpersonal relationships are the core of the care practices for patients with SPMI and which are confronted with existential suffering.

Firstly, from the point of view of psychiatric nurses we gained significant insight into the development and depth of the care relationship with the special nature of existential suffering. In our findings we describe a concretization of a relation based type of care or person centered care (Baart \& Vosman 2011). The development and deepening of the care relation requires a subtle process of feeling, empathy, scanning, balancing and 
respect in dealing with the patient. These qualities are all part of the unique role of the psychiatric nurse, as well as crucial for the experience of meaningfulness on the side of the patient. In a recent qualitative study on end-of-life perspectives and expectations of patients with schizophrenia, it is clear that from their perspective they want to receive a highly personalized care within a trusting relationship with skilled caregivers (Sweers et al. 2013). Apart from the importance of the relation based care, the necessity of contextual preconditions in order to realize this type of care is equally important. In this regard it is striking that the recurring complaints of the nurses about understaffing and the lack of single rooms do not harmonize with the importance, as indicated by our interviewees, of building a personal caring relationship in the context of a holistic approach with attention to all dimensions of being a person. One has to ask whether the residential settings is able to meet the standards of a person centered care for patients with SPMI. In Belgium and the Netherlands for example intramural residential care is cut back in favor of different forms of (less costly) extramural home care. Nevertheless one has to bear in mind that SPMI patients are a vulnerable population. People with long-term mental illness who live in the community often experience social and existential alienation (Erdner et al. 2005). Moreover, patients with severe mental illness consider caregivers as their best friends (Nyström et al. 2002).

Secondly, this study provides a concretization of a possible "palliative" or supporting approach in chronic mental health. In general, relevant research concerning palliative care for psychiatric patients is lacking and mostly limited to the description of physical unbearable suffering in patients with terminal illnesses (Woods et al. 2008; Sweers et al. 2011). The focus on physical suffering at the end of life is more dominant regarding the history of palliative care. Difficult questions about existential meaningfulness and how to deal with existential suffering of non-terminally ill patients remain open. The existential suffering related to psychiatric illness is difficult to define or quantify. Nevertheless in recent discussions about somatic palliative care there is a shift towards more attention to the existential dimension as well in order to sustain a holistic care perspective (Leget 2012).

In light of the results reported above, we may ask what is specifically new and particular in these qualitative empirical data. When we look at both empirical studies on the caring relationship of nurses with palliative patients in somatic care as well as empirical studies on the general care provided by psychiatric nurses, we can identify some recurring points of interest, such as the nurse-patient relationship as the central event 
and the holistic approach of the patient (Gastmans 1998; Gommers et al. 2010). We may therefore formulate the hypothesis that there is a structural similarity between psychiatric care and palliative care. Bearing this in mind, we can rightly ask why palliative care remains virtually non-existent in residential psychiatric care. In other words, we might have identified a contradiction in the workfield (McGrath \& Holewa 2004). 


\section{REFERENCES}

Baart A \& Vosman F. Relationship Based Care and Recognition. Part Two: Good Care and Recognition. In: Leget C., Gastmans C., Verkerk M. (eds). Care, Compassion and Recognition: An Ethical Discussion. Leuven: Peeters, 2011.

Chang C-K, Hayes R, Perera G, Broadbent M, Fernandez A, Lee W, Hotopf M, Steward R. Life expectancy at birth for people with serious mental illness and other major disorders from a secondary mental health care case register in London. PLoS ONE 6(5): e19590. doi:10.1371/journal.pone.0019590.

Corbin J, Strauss A. Basics of qualitative research: Techniques and procedures for developing grounded theory, Thousand Oaks/London/New Delhi: Sage Publications Inc., 2008.

De Hert M, Dekker J, Wood D, Kahl K, Holt I, Möller J. Cardiovascular disease and diabetes in people with severe mental illness position statement from the European Psychiatric Association (EPA), supported by the European Society of Cardiology (ESC). European Psychiatry, 2009, 24: 412-424.

Denzin N \& Lincoln Y. (eds) Handbook of Qualitative Research, 2nd edn, London: Sage Publications, 2000.

Dierckx de Casterlé B, Gastmans C, Bryon E, Denier Y. QUAGOL: A guide for qualitative data analysis. International Journal of Nursing Studies, 2012, 49: 360-371. Ellison N. Mental Health and Palliative Care: Literature Review. London: Mental Health Foundation, 2008.

Erdner A, Anderson L, Magnusson A, Lützén K. Varying Views of Life Among People With Long-term mental illness. Journal of Psychiatric and Mental Health Nursing, 2009, 16: 54-60.

Erdner A, Magnusson A, Nyström M, Lützén K. Social and Existential Alienation Experienced by People with Long-Term Mental Illness. Scandinavian Journal of Caring Sciences, 2005, 19: 373-380.

Federal Control and Evaluation Committee on Euthanasia. 2014. Sixth Report to the Constitutive Chamber (in Dutch, French). Brussels.

Gastmans C. Interpersonal Relations in Nursing: A Philosophical-Ethical Analysis of the Work of Hildegard E. Peplau. Journal of Advanced Nursing, 1998, 28: 1312-1319. 
Gommers J, Van Audenhove C, Van Ertvelde J. De psychiatrisch verpleegkundige: vakkundig in balans. Professionalisering van de verantwoordelijk verpleegkundige in de geestelijke gezondheidszorg, Antwerp: Garant, 2010.

Haekens A \& Hermans J (eds.). Geen eind aan mijn pijn? Over uitzichtloos psychisch lijden. Antwerpen: Garant, 2008.

Hem M \& Heggen. Being professional and being human: one nurse's relationship with a psychiatric patient. Journal of Advanced Nursing, 2003, 43: 101-108.

Laursen T. Life Expectancy among Persons with Schizophrenia or Bipolar Affective Disorder. Schizophrenia Research, 2011: 31, 101-104.

Leget C. Implementing spiritual care at the end of life: the Netherlands. Where's the humanity? European Journal of Palliative Care, 2012, 19: 191-192.

Lloyd-Williams M, Abba K, Crowther J. Supportive and Palliative Care for patients with Chronic Mental Illness Including Dementia. Current Opinion in Supporting Palliative Care, 2014, 8: 303-307.

Luxembourg Euthanasia Law. 2009. Memorial Official Journal of the Grand Duchy of Luxembourg of March 16.

McGrath P, Holewa H. Mental Health and Palliative Care: Exploring the Ideological Interface. International Journal of Psychosocial Rehabilitation, 2004, 9: 107-119.

Nyström M, Dahlberg K, Segesten K. The Enigma of Severe Mental Illness: A Swedish perspective. Issues in Mental Health Nursing, 2002: 23, 121-134.

Ruggeri M, Leese M, Thornicroft G, Bisoffi G, Tansella M. Definition and prevalence of severe and persistent mental illness. British Journal of Psychiatry. 2000, 177: 149155.

Sweers K, De Hert M, Detraux J. Een menswaardige palliatieve zorgverlening voor patiënten met een (ernstige) psychiatrische stoornis: utopie of noodzaak? Psychiatrie \& Verpleging, 2011, 87: 156-170.

Sweers K, Dierckx de Casterlé B, Detraux J, De Hert M. End-of-Life (Care) Perspectives and Expectations of Patients With Schizophrenia. Archives of Psychiatric Nursing, 2013, 27: 246-252.

The Belgian Act concerning Palliative Care. 2002. Belgian Law Gazette of October 16.

The Belgian Act on Euthanasia. 2002. Belgian Law Gazette of June 22.

The Dutch Termination of life on request and assisted suicide (Review Procedures)Act. 2002. 
Wagner L, Torrez-González F, Geidel A, King M. Existential questions in schizophrenia: perceptions of patients and caregivers. Rev Saude Publica, 2011, 45: 401-408.

World Health Organization (2002). WHO Definition of Palliative Care. Available at: http://www.who.int/cancer/palliative/definition/en/, accessed at 20/08/2015

Woods A, Willison K, Kington C, Gavin A. Palliative care for people with severe mental illness: A review of the literature. The Canadian Journal of Psychiatry, 2008, 53: 725-736. 